\title{
Obstructive sleep apnoea is associated with diabetes in sleepy subjects
}

\author{
P E Ronksley, ${ }^{1}$ B R Hemmelgarn, ${ }^{1,2}$ S J Heitman, ${ }^{1,2}$ P J Hanly, ${ }^{2}$ P D Faris, ${ }^{1}$ H Quan, ${ }^{1}$ \\ W H Tsai ${ }^{1,2}$
}

${ }^{1}$ Department of Community Health Sciences, Faculty of Medicine, University of Calgary, Calgary, Canada; ${ }^{2}$ Department of Medicine, Faculty of Medicine, University of Calgary, Calgary, Canada

Correspondence to:

Dr W H Tsai, Departments of

Medicine and Community Health

Sciences, Rockyview General

Hospital, 7007 14th St SW,

Calgary, Alberta, Canada, T2V

1P9; tsai@ucalgary.ca

Received 10 February 2009

Accepted 2 August 2009

Published Online First

10 August 2009

\begin{abstract}
Background: Although obstructive sleep apnoea (OSA)

has been linked to insulin resistance and glucose

intolerance, it is unclear whether there is an independent association between OSA and diabetes mellitus (DM) and whether all patients with OSA are at risk. The objective of this study was to determine the association between OSA and DM in a large cohort of patients referred for sleep diagnostic testing.
\end{abstract}

Methods: A cross-sectional analysis of participants in a clinic-based study was conducted between July 2005 and August 2007. DM was defined by self-report and concurrent use of diabetic medications (oral hypoglycaemics and/or insulin). Sensitivity analysis was performed using a validated administrative definition of diabetes. OSA was defined by the respiratory disturbance index (RDI) using polysomnography or ambulatory monitoring. Severe OSA was defined as an RDI $\geqslant 30 / h$. Subjective sleepiness was defined as an Epworth Sleepiness Scale score $\geqslant 10$.

Results: Complete data were available for 2149 patients. The prevalence of DM increased with increasing OSA severity $(p<0.001)$. Severe OSA was associated with DM following adjustment for patient demographics, weight and neck circumference lodds ratio (OR) 2.18; 95\% Cl 1.22 to $3.89 ; p<0.01)$. Following a stratified analysis, this relationship was observed exclusively in sleepy patients (OR 2.59 (95\% Cl 1.35 to 4.97 ) vs 1.16 (95\% Cl 0.31 to 4.37) in non-sleepy patients).

Conclusions: Severe OSA is independently associated with DM in patients who report excessive sleepiness. Future studies investigating the impact of OSA treatment on DM may wish to focus on this patient population.

Severe OSA has been reported to be independently associated with cardiovascular disease and death. ${ }^{1-4}$ More recently, OSA has been associated with increased insulin resistance, ${ }^{5-7}$ but it is unclear whether there is an independent relationship with diabetes mellitus (DM).

Previous studies evaluating the association between OSA and DM have been limited by the lack of an objective measure of $\mathrm{OSA}^{89}$ and the absence of a robust definition of DM. ${ }^{10}{ }^{11}$ In contrast, the Sleep Heart Health Study evaluated 2656 patients in a clinic-based cross-sectional sample ${ }^{12}$ and reported an independent association between OSA and glucose intolerance. The Wisconsin Sleep Cohort study also demonstrated an independent association between OSA and DM. ${ }^{13}$ However, the absence of an increased incidence of DM in the longitudinal follow-up of this cohort raises some doubts about the strength of association between these two conditions.
Moreover, a recent randomised control trial by West et al failed to find any improvement in glycaemic control or insulin resistance in 42 patients following continuous positive airway pressure (CPAP) therapy. ${ }^{14}$

The inability to identify "at-risk" patients may explain the heterogeneity of the results. An association between OSA severity and cardiovascular risk has been established in several studies. ${ }^{1-4}$ More recently, the notion that non-sleepy patients with OSA may represent a different risk stratum than sleepy patients has been raised. ${ }^{15}$ The identification of subgroups of patients with OSA at increased risk of developing DM would be helpful in assessing therapeutic strategies. Thus, the primary objective of this study was to determine the association between OSA severity and DM given the potential that only some patients with OSA are at increased risk for DM. The secondary objective was to investigate whether patients with OSA who report sleepiness have a greater risk of DM than those who do not.

\section{METHODS \\ Study population}

This project was part of a larger study investigating healthcare utilisation among patients with OSA. Between July 2005 and August 2007 we included all patients aged $>18$ years who were referred for sleep diagnostic testing at either the Foothills Medical Centre or private respiratory care companies within the Calgary Health Region (population $\sim 1.3$ million). Over the recruitment period, nearly all sleep diagnostic testing was conducted in these facilities. We excluded patients who had a previous diagnosis of OSA or had prior sleep diagnostic testing (polysomnography or ambulatory monitoring).

Within the Calgary Health Region virtually all patients undergo ambulatory monitoring as their initial sleep diagnostic test. Consequently, most of the patients undergoing polysomnography at the Foothill Medical Centre Sleep Centre have already undergone ambulatory monitoring and were not included within the polysomnography group.

Baseline clinical and demographic information was collected for all participants prior to sleep diagnostic testing. This included age, gender, body mass index (BMI), neck circumference, smoking status (self-reported) and home address. Each participant also completed the Epworth Sleepiness Scale (ESS), a self-administered questionnaire that provides a measure of daytime sleepiness. ${ }^{16}$ Co-morbidity was determined through the use of a questionnaire administered by trained 
personnel in which patients were asked to report the presence of specific co-morbidities including hypertension, asthma, depression, cardiac arrhythmia, myocardial infarction, chronic obstructive pulmonary disease (COPD), diabetes, heart failure and stroke. Patients also listed their current medications.

\section{Study variables}

\section{Obstructive sleep apnoea (OSA)}

OSA was diagnosed by ambulatory monitoring at home with the Remmers Sleep Recorder or by attended polysomnography in the sleep laboratory at Foothills Medical Centre. OSA severity was defined by the respiratory disturbance index (RDI) as follows: no OSA (RDI $<5 / \mathrm{h})$, mild OSA (RDI $=5$ $14.9 / \mathrm{h}$ ), moderate OSA (RDI $=15-29.9 / \mathrm{h}$ ) and severe OSA (RDI $\geqslant 30 / \mathrm{h}$ ). Moderate OSA was defined based on Medicare funding criteria $(R D I \geqslant 15 / h$ ). The definition for severe OSA was based on cohort studies which linked severe OSA (RDI $\geqslant 30 / h$ ) with hypertension, myocardial infarction, stroke or death. ${ }^{1-4}$

\section{Polysomnography}

Polysomnographic data were recorded by a computerised system (Sandman Elite Version 8.0, Nellcor Puritan Bennett (Melville) Ltd, Kanata, Ontario, Canada). This included a standardised montage: three electroencephalograms (EEGs) (C4/A1, C3/A2, O1/A2), bilateral electro-oculograms (EOG), submental electromyogram (EMG), bilateral leg EMGs and electrocardiography (ECG). Airflow was measured using a nasal pressure transducer (Braebon Medical, Ontario, Canada). Respiratory effort was assessed by inductance plethysmography (Respitrace Ambulatory Monitoring, Ardsley, New York, USA) and oxygen saturation was recorded by oximetry (953 Finger Flex Sensor; Healthdyne Technologies, Georgia, USA).

The RDI was defined as the number of apnoeas and hypopnoeas per hour of sleep. Apnoea was defined as a cessation of airflow for at least $10 \mathrm{~s}$. Hypopnoea was defined as an abnormal respiratory event lasting $10 \mathrm{~s}$ or more, with at least a $30 \%$ reduction in thorocoabdominal movement or airflow compared with baseline and associated with at least a $4 \%$ oxygen desaturation.

\section{Ambulatory monitoring}

The Remmers Sleep Recorder (SagaTech Electronics, Calgary, Canada) is an ambulatory monitor that measures snoring, oxygen saturation, respiratory airflow (by monitoring nasal pressure) and body position. The RDI is derived from automated analysis of the oximetry signal using a $4 \%$ desaturation threshold. This algorithm uses both shape and magnitude of oxygen desaturation to score respiratory events. ${ }^{17}$ Ambulatory studies are manually reviewed by the interpreting physician with the flow signal being used for quality assurance purposes. Ambulatory studies are repeated if there are discrepancies between the automatically scored respiratory events and the airflow channel. This monitor has excellent agreement with the polysomnographically determined apnoea-hypopnoea index (AHI) ${ }^{17}$ It has also been validated as a clinical management tool. ${ }^{18} 19$

\section{Diabetes mellitus (DM)}

DM was defined by self-report and concurrent use of diabetic medications (oral hypoglycaemic drugs and/or insulin). Sensitivity analysis was performed with a validated administrative algorithm. ${ }^{20}$ Using the patient's unique Provincial Health Number (PHN), the cohort was linked to two Alberta Health and Wellness administrative databases, the hospitalisation discharge database and the physician claims database. For each patient, all hospitalisation and physician claims information was obtained for a 2-year period prior to sleep diagnostic testing. The administrative algorithm defines diabetes by either one hospitalisation with a diagnosis of DM or two physician claims for DM within a 2-year period. It has a sensitivity of $86 \%$ and a specificity of $97 \%$.

\section{Co-morbidity}

Validated algorithms were used within the questionnaire to define each co-morbid condition (in addition to DM). ${ }^{21-25}$ These algorithms were further supplemented by the ICD-10 coding scheme developed by Quan et al. ${ }^{26}$ For co-morbidities that did not have validated algorithms (specifically COPD, depression and cardiac arrhythmia), ICD-9-CM and ICD-10 diagnostic codes were identified within the ICD-9-CM and ICD-10 manuals. ${ }^{27}{ }^{28}$ Within the administrative datasets, the condition was considered present if the algorithm defining the condition was satisfied. Co-morbidities that did not have a validated algorithm were considered present if at least one diagnostic code for the condition within either the physician claims data or hospitalisation data was recorded within the 2-year period prior to sleep diagnostic testing.

\section{Statistical analysis}

Patient characteristics were described using mean (standard deviation, SD) for normally distributed variables. In cases of highly skewed or clearly non-normal distributions, the median (interquartile range, IQR) were reported. Means and proportions were compared using analysis of variance and $\chi^{2}$ tests, respectively. The Kruskal-Wallis test was used to compare skewed variables. Baseline characteristics were stratified by OSA severity.

To determine the relationship between OSA severity and prevalent DM, multivariate logistic regression with backward selection techniques was used. Significant predictors of DM were identified by univariate analysis. Saturated multivariate models were constructed using these significant predictors. In addition, relevant interaction terms were developed. These included OSA severity $\times$ sleepiness. We developed further reduced models based on the presence or absence of effect modification and confounding by the specified predictors. The fit of each model was also assessed by the likelihood ratio test.

Crude odds ratios (OR) for prevalent DM were calculated by comparing the odds of DM in each of the three severity levels of OSA (mild: RDI 5-14.9; moderate: RDI 15-29.9; severe: RDI $\geqslant 30$ ) with the odds of DM in those without OSA (RDI <5). A logistic regression model was employed to obtain ORs after adjustment for age, gender, BMI, neck circumference and smoking status. BMI was modelled as a continuous and categorical variable (normal weight $\left(<25 \mathrm{~kg} / \mathrm{m}^{2}\right)$, overweight $\left(25-29.9 \mathrm{~kg} / \mathrm{m}^{2}\right)$ and obese $\left.\left(\geqslant 30 \mathrm{~kg} / \mathrm{m}^{2}\right)\right)$. There were no differences in the ORs when BMI was modelled in either format, so BMI was treated as a categorical variable for ease of interpretation. Age was also modelled as a continuous and categorical variable. When modelled as a categorical variable, subjects were categorised as $\geqslant 65$ years or $<65$ years of age. Continuous age and BMI were assessed for non-linearity by the likelihood ratio test of its squared and cubic terms. The linearity assumption was not violated in either variable.

A sensitivity analysis was performed in which similar models were developed using the validated administrative algorithm to 
define prevalent DM as the outcome variable. A stratified analysis was performed in which crude and adjusted ORs for prevalent DM were generated by the level of daytime sleepiness. A participant was considered sleepy if ESS $\geqslant 10$. Finally, a sensitivity analysis for the type of diagnostic test (ambulatory monitoring or polysomnography) was conducted.

For all statistical tests, $\mathrm{p}<0.05$ was considered statistically significant. All analyses were performed using STATA 10.0 (Statacorp, College Station, Texas, USA).

\section{RESULTS}

From July 2005 to August 2007, 2295 patients were referred for sleep diagnostic testing, of whom 78 (3.4\%) refused to participate and 42 (1.8\%) lived outside Alberta and were therefore excluded. Of the remaining 2175 patients, $26(1.2 \%)$ were excluded because they were absent from the Alberta Health and Wellness registry, which resulted in a final study population of 2149. Figure 1 summarises the recruitment process and diagnostic testing. Characteristics of the study population are summarised in table 1 . There were 1346 men and 803 women, with a median BMI of $31.3 \mathrm{~kg} / \mathrm{m}^{2}$ (IOR 27.3-36.6) and mean (SD) age of 50.1 (12.9) years. Based on RDI criteria, 432 patients (20.1\%) did not have OSA, 738 (34.3\%) had mild

Figure 1 Patient flow diagram. AHW, Alberta Health and Wellness.
OSA, $443(20.6 \%)$ had moderate OSA and 536 (24.9\%) had severe OSA.

The overall prevalence of DM was $8.1 \%$, which increased as OSA severity increased $(p<0.001$, table 1$)$. A number of other variables also increased in association with OSA severity including age, BMI, neck circumference and ESS $(\mathrm{p}<0.001)$. Furthermore, co-morbidities such as hypertension, myocardial infarction, heart failure and stroke increased in association with OSA severity (table 2).

DM was associated with severe OSA (table 3). The unadjusted OR for DM with severe OSA was 3.93 (95\% CI 2.34 to $6.58, p<0.001)$. This relationship was not significant in patients with mild OSA (OR 1.25 (95\% CI 0.71 to 2.18 , $\mathrm{p}=0.44)$ ) or moderate OSA (OR 1.75 (95\% CI 0.98 to 3.13 , 0.06)). Nevertheless, there was a dose-response relationship between the severity of OSA and the prevalence of DM ( $p$ value for trend $<0.001$ ).

Following adjustment for age, BMI, gender, neck circumference and smoking status, the OR for the presence of DM was $2.18(95 \%$ CI 1.22 to $3.89, p=0.008)$ in patients with severe OSA, but the OR for DM was not statistically significant in patients with mild or moderate OSA. Furthermore, modifying the definition of DM did not alter the relationship. Using a

Total number of participants referred for sleep assessment $(n=2295)$

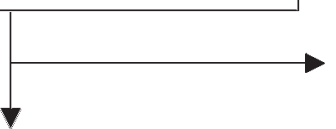

Number refused consent $(n=78)$

Number of consented participants referred for sleep assessment $(n=$ 2217)

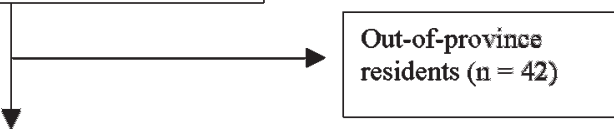

Number of Alberta residents sent to AHW for data linkage $(n=2175)$

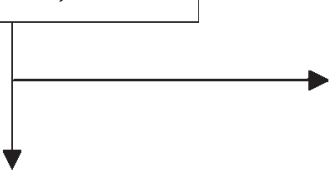

Number of patients not identified in AHW registry file $(\mathrm{n}=26)$

Participants with complete sleep test data and linked to $\mathrm{AHW}$ registry file $(n=2149)$

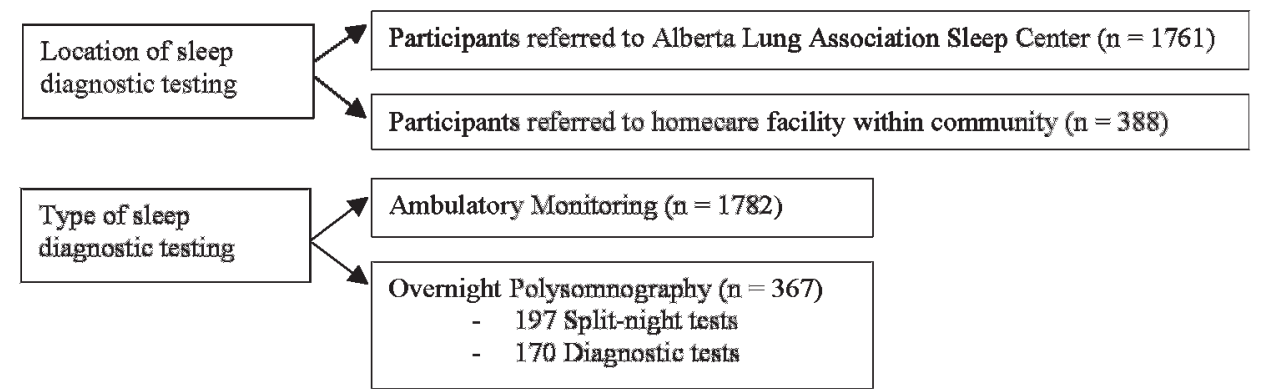


Table 1 Demographic characteristics of study patients $(n=2149)$

\begin{tabular}{|c|c|c|c|c|c|c|}
\hline & $\begin{array}{l}\text { No OSA } \\
(\text { RDI }<5)\end{array}$ & $\begin{array}{l}\text { Mild OSA } \\
\text { (RDI 5-14.9) }\end{array}$ & $\begin{array}{l}\text { Moderate OSA } \\
\text { (RDI 15-29.9) }\end{array}$ & $\begin{array}{l}\text { Severe OSA } \\
(\mathrm{RDI} \geqslant 30)\end{array}$ & All & p Value* \\
\hline Observations, n (\% all) & $432(20.1)$ & $738(34.4)$ & $443(20.6)$ & $536(24.9)$ & $2149(100)$ & $<0.001$ \\
\hline Men, n (\%) & $197(45.6)$ & $463(62.7)$ & $281(63.4)$ & $405(75.6)$ & $1346(62.6)$ & $<0.001$ \\
\hline Mean (SD) age (years) & $44.0(12.9)$ & $50.0(12.5)$ & $52.8(12.5)$ & $53.0(11.9)$ & $50.1(12.9)$ & $<0.001$ \\
\hline Median (IOR) BMI $\left(\mathrm{kg} / \mathrm{m}^{2}\right)$ & $27.8(24.9-32.2)$ & $30.6(27.2-35.4)$ & $32.0(28.1-36.8)$ & $34.5(30.4-39.8)$ & $31.3(27.3-36.6)$ & $<0.001$ \\
\hline Current smoker, n (\%) & $89(20.6)$ & $116(15.8)$ & $60(13.5)$ & $89(16.6)$ & $354(16.5)$ & 0.11 \\
\hline $\begin{array}{l}\text { Mean (SD) neck } \\
\text { circumference (in) }\end{array}$ & $14.9(1.5)$ & $15.8(1.7)$ & $16.3(1.7)$ & $17.1(1.8)$ & $16.0(1.9)$ & $<0.001$ \\
\hline Mean (SD) ESS & $10.9(5.1)$ & $10.7(5.3)$ & $11.4(5.4)$ & $12.3(5.5)$ & $11.3(5.4)$ & $<0.001$ \\
\hline $\begin{array}{l}\text { Diabetes (self-report }+ \\
\text { medications), } \mathrm{n}(\%)\end{array}$ & $19(4.4)$ & $40(5.4)$ & $33(7.4)$ & $82(15.3)$ & $174(8.1)$ & $<0.001$ \\
\hline $\begin{array}{l}\text { Diabetes (admin algorithm), } \mathrm{n} \\
(\%)\end{array}$ & $29(6.7)$ & $61(8.3)$ & $42(9.5)$ & $111(20.7)$ & $243(11.3)$ & $<0.001$ \\
\hline
\end{tabular}

BMI, body mass index; ESS, Epworth Sleepiness Score; IQR, interquartile range; OSA, obstructive sleep apnoea; RDI, respiratory disturbance index; SD, standard deviation. ${ }^{*} \chi^{2}$ test, analysis of variance.

validated administrative algorithm, the OR for the presence of DM in patients with severe OSA was 1.82 (95\% CI 1.07 to 3.10 , $p=0.027)$. However, using the administrative algorithm, the relationship between severe OSA and DM was attenuated and non-significant when age was modelled as a continuous variable (OR for severe OSA 1.57 (95\% CI 0.87 to 2.83), $\mathrm{p}=0.14$ ).

A stratified analysis was performed to assess the influence of sleepiness on the OR of prevalent DM (table 4). Severe OSA was associated with DM exclusively in sleepy patients (ESS $\geqslant 10$ ). This was observed in both the unadjusted models (sleepy severe OSA: OR 4.11 (95\% CI 2.30 to 7.33) vs non-sleepy severe OSA: OR 2.79 (95\% CI 0.87 to 9.00)) and fully adjusted models (sleepy severe OSA: OR 2.59 (95\% CI 1.35 to 4.97) vs non-sleepy severe OSA: OR 1.16 (95\% CI 0.31 to 4.37$)$ ).

\section{Sensitivity analysis}

Sensitivity analysis was performed using a full model including co-morbidities, medication class and oxygen saturation profile. The association between OSA and DM remained unchanged using a full model including co-morbidities and medications. Furthermore, the association was still observed whether the patients had undergone ambulatory monitoring or polysomnography. After the exclusion of patients undergoing polysomnography, the association between OSA and DM remained (OR 1.92 (95\% CI 1.03 to 3.59$), p=0.040$ ).

Hypoxaemia was not independently associated with DM when analysed as a continuous variable (percentage time spent below oxygen saturation $\left.\left(\mathrm{SaO}_{2}\right)=90 \%, \mathrm{p}=0.36\right)$ or as a categorical variable $\left(12 \%\right.$ spent below $\left.\mathrm{SaO}_{2}=90 \%, \mathrm{p}=0.60\right)$. Furthermore, the inclusion of measures of hypoxaemia within the logistic models did not alter the significant association between severe OSA and DM in sleepy subjects (OR 2.47 (95\% CI 1.23 to 4.98$), p=0.011$ ).

\section{DISCUSSION}

$\mathrm{DM}$ is associated with severe OSA (RDI $\geqslant 30 / \mathrm{h}$ ). This association remains statistically significant even after adjustment for age, BMI, gender, neck circumference and smoking status. However, this relationship appears to be limited to patients who report excessive daytime sleepiness.

Our findings complement what has already been observed in other large cohort studies. The Sleep Heart Health Study confirmed the diagnosis of OSA objectively with unattended home polysomnography and found an independent association between OSA and glucose intolerance in a subset of 2656 patients. ${ }^{12}$ However, it remains unclear if patients with glucose intolerance are at the same risk of micro/macrovascular disease as those with DM. The Wisconsin Sleep Cohort Study $(n=1387)$ reported an independent association between OSA diagnosed by attended polysomnography and a robust definition of DM (physician diagnosis or glucose control). These findings differed from ours in that the association between OSA and DM existed at all levels of OSA severity without an apparent dose-response relationship. Our findings are more consistent with previous studies where the risk of cardiovascular disease and death was restricted to those with severe OSA. ${ }^{142930}$ A novel finding in our study was that the association between OSA and DM occurred only in patients who reported excessive daytime sleepiness. The notion that patients with OSA who are sleepy have a different risk profile from those who are not sleepy has been raised in the context of long-term cardiovascular disease and the response to CPAP

Table 2 Patient co-morbidities stratified by OSA severity $(n=2149)$

\begin{tabular}{|c|c|c|c|c|c|c|}
\hline Co-morbidity & $\begin{array}{l}\text { No OSA } \\
(n=432)\end{array}$ & $\begin{array}{l}\text { Mild OSA } \\
(n=738)\end{array}$ & $\begin{array}{l}\text { Moderate OSA } \\
(\mathrm{n}=443)\end{array}$ & $\begin{array}{l}\text { Severe OSA } \\
(\mathrm{n}=536)\end{array}$ & $\begin{array}{l}\text { All } \\
(n=2149)\end{array}$ & p Value* \\
\hline Hypertension, n (\%) & $83(19.2)$ & $205(27.8)$ & $183(41.3)$ & $243(45.3)$ & $714(33.2)$ & $<0.001$ \\
\hline Depression, n (\%) & $128(29.6)$ & $202(27.4)$ & $123(27.8)$ & $120(22.4)$ & $573(26.7)$ & 0.027 \\
\hline Asthma, n (\%) & $53(12.3)$ & $78(10.6)$ & $63(14.2)$ & $53(9.9)$ & $247(11.5)$ & 0.59 \\
\hline COPD, n (\%) & $15(3.5)$ & $24(3.3)$ & $15(3.4)$ & $23(4.3)$ & $77(3.6)$ & 0.44 \\
\hline Myocardial infarction, n (\%) & $4(0.9)$ & $15(2.0)$ & $8(1.8)$ & $26(4.9)$ & $53(2.5)$ & $<0.001$ \\
\hline Heart failure, n (\%) & $2(0.5)$ & $9(1.2)$ & $5(1.1)$ & $13(2.4)$ & $29(1.3)$ & 0.012 \\
\hline Stroke, n (\%) & $0(0)$ & $1(0.1)$ & $3(0.7)$ & $5(0.9)$ & $9(0.4)$ & 0.008 \\
\hline
\end{tabular}

COPF, chronic obstructive pulmonary disease; OSA, obstructive sleep apnoea.

${ }^{*} \chi^{2}$ test (3 degrees of freedom). 
Table 3 Odds of prevalent diabetes mellitus by OSA severity

\begin{tabular}{|c|c|c|c|c|c|c|}
\hline & \multicolumn{2}{|l|}{ Unadjusted model } & \multicolumn{2}{|c|}{ Adjusted for age and gender } & \multicolumn{2}{|c|}{ Multivariate adjusted model ${ }^{*}$} \\
\hline & OR (95\% Cl) & p Value & OR (95\% Cl) & p Value & OR (95\% Cl) & p Value \\
\hline \multicolumn{7}{|c|}{ Definition: Diabetes (self-report + medications) } \\
\hline Mild OSA & 1.25 (0.71 to 2.18$)$ & 0.44 & 1.21 (0.69 to 2.13 ) & 0.51 & 0.95 (0.53 to 1.71$)$ & 0.86 \\
\hline Moderate OSA & $1.75(0.98$ to 3.13$)$ & 0.059 & 1.65 (0.91 to 2.97$)$ & 0.10 & $1.02(0.54$ to 1.93$)$ & 0.94 \\
\hline Severe OSA & 3.93 (2.34 to 6.58$)$ & $<0.001$ & 3.79 (2.23 to 6.45$)$ & $<0.001$ & 2.18 (1.22 to 3.89$)$ & 0.008 \\
\hline Test for trend & & $<0.001$ & & $<0.001$ & & 0.005 \\
\hline \multicolumn{7}{|c|}{$\begin{array}{l}\text { Definition: Diabetes administrative algorithm (two physician claims or one } \\
\text { hospitalisation within a 2-year period) }\end{array}$} \\
\hline Mild OSA & 1.25 (0.79 to 1.98$)$ & 0.34 & 1.14 (0.72 to 1.82$)$ & 0.58 & $0.90(0.53$ to 1.53$)$ & 0.70 \\
\hline Moderate OSA & 1.46 (0.89 to 2.38$)$ & 0.14 & 1.26 (0.76 to 2.09$)$ & 0.36 & 0.88 (0.49 to 1.58$)$ & 0.68 \\
\hline Severe OSA & $3.63(2.36$ to 5.58$)$ & $<0.001$ & 3.18 (2.04 to 4.95$)$ & $<0.001$ & $1.82(1.07$ to 3.10$)$ & 0.027 \\
\hline Test for trend & & $<0.001$ & & $<0.001$ & & 0.035 \\
\hline
\end{tabular}

$\mathrm{Cl}$, confidence interval; $\mathrm{OR}$, odds ratio; OSA, obstructive sleep apnoea.

Reference group is patients with no OSA.

*Multivariate model adjusted for age, gender, body mass index, neck circumference and smoking status.

therapy. ${ }^{15} 3132$ Similarly, our study suggests that a reported history of sleepiness may help to identify patients with OSA who have an increased risk of DM.

Although previous literature has shown an association between intermittent hypoxia/OSA and both insulin levels and insulin resistance, ${ }^{53} 34$ in this population hypoxaemia was not independently associated with DM nor did the inclusion of measures of hypoxaemia alter the association between severe OSA and DM in sleepy patients. It is entirely possible that sleepiness is acting as a marker of the sleep disrupting effects of OSA, independent of hypoxaemia. It has been shown that isolated sleep fragmentation or sleep deprivation may also result in cardiovascular and metabolic effects. ${ }^{35-38}$ A study by Morrell et al showed that sleep fragmentation was associated with elevated systemic blood pressure in people with an AHI $<1$ event/h. ${ }^{35}$ Furthermore, sleep fragmentation has been shown to augment sympathetic nervous activity, resulting in higher metabolic rates during sleep and increased catecholamine secretion. $^{\text {737-39 }}$

The association between sleepiness and DM is also biologically plausible. Specifically, the presence of abnormally high sympathetic output has been proposed as a potential mechanism for the association between OSA and insulin resistance/ glucose intolerance. ${ }^{73} 3840$ Earlier work by Spiegel et al showed that sleep debt significantly affected carbohydrate metabolism and endocrine function. ${ }^{40}$ In a sample of healthy men, six nights of restricted sleep resulted in significant increases in sympathetic nervous activity, glucose intolerance and raised evening cortisol levels. It has been hypothesised that raised evening cortisol levels may reflect impairment in the negative feedback control of the hypothalmo-pituitary-adrenal axis resulting in insulin resistance. ${ }^{41}$ Finally, Vgontzas et al has shown that raised plasma levels of inflammatory cytokines such as tumour necrosis factor $\alpha$ and interleukin 6 in patients with sleep disorders including OSA are also associated with excessive daytime sleepiness. ${ }^{38}$

Our study has several limitations. First, it is possible that we underestimated the prevalence of DM since our definition required both a report of physician-diagnosed diabetes and the use of specific medication (oral hypoglycaemic drugs and/or insulin). Consequently, patients whose DM was treated with lifestyle modification or who were prescribed medication but did not use it would not have been identified as having DM. Notwithstanding this limitation, sensitivity analysis using the validated administrative algorithm did not alter our results.

Second, it is possible that we did not adequately account for the confounding effect of adiposity through the measurement of BMI and neck circumference alone. It has been established that BMI does not discriminate between muscle and adipose tissue or provide an assessment of body fat distribution. Thus, residual confounding may result in an overestimate of the true association between OSA and DM.

Third, subjects were recruited from patients referred for sleep diagnostic testing, which raises the possibility of referral bias. However, all patients seen at private respiratory companies as well as at the sleep centre had sleep diagnostic testing prior to

Table 4 Odds of prevalent diabetes mellitus by OSA severity (stratified by level of daytime sleepiness)

\begin{tabular}{|c|c|c|c|c|}
\hline & \multicolumn{2}{|l|}{ Sleepy (ESS $\geqslant 10$ ) } & \multicolumn{2}{|c|}{ Non-sleepy (ESS < 10) } \\
\hline & OR $(95 \% \mathrm{CI})$ & p Value & OR $(95 \% \mathrm{CI})$ & p Value \\
\hline \multicolumn{5}{|l|}{ Unadjusted model } \\
\hline Mild OSA & 1.24 (0.65 to 2.38 ) & 0.51 & $1.47(0.47$ to 4.60$)$ & 0.51 \\
\hline Moderate OSA & $1.70(0.87$ to 3.32$)$ & 0.12 & 2.03 (0.61 to 6.76$)$ & 0.25 \\
\hline Severe OSA & $4.11(2.30$ to 7.33$)$ & $<0.001$ & $2.79(0.87$ to 9.00$)$ & 0.09 \\
\hline \multicolumn{5}{|c|}{ Multivariate adjusted model* } \\
\hline Mild OSA & $0.98(0.50$ to 1.94$)$ & 0.96 & $0.94(0.28$ to 3.17$)$ & 0.92 \\
\hline Moderate OSA & $1.13(0.54$ to 2.32$)$ & 0.75 & 0.820 .21 to 3.14 ) & 0.77 \\
\hline Severe OSA & 2.59 (1.35 to 4.97$)$ & 0.004 & $1.16(0.31$ to 4.37$)$ & 0.83 \\
\hline
\end{tabular}

Cl, confidence interval; ESS, Epworth Sleepiness Scale; OR, odds ratio; OSA, obstructive sleep apnoea.

Reference group is patients with no OSA.

*Multivariate model adjusted for age, gender, body mass index, neck circumference and smoking status. 
consultation with a sleep physician. Our patient population was not selected by sleep physicians but rather reflects those in the community who are suspected of having OSA by their primary care physician.

Finally, the use of ambulatory monitoring rather than attended polysomnography to determine RDI may be regarded as a limitation. However, the ambulatory monitor we used has been validated against polysomnography, both in terms of bias and in the clinical management of OSA. ${ }^{17-19}$ While the monitor has not been validated in patients with co-morbidities, sensitivity analysis accounting for co-morbidities or measures of hypoxaemia did not change the results.

In summary, OSA is associated with DM in this referred population, but only in those with severe disease (RDI $\geqslant 30 / h$ ) who report excessive sleepiness. Further investigation is required to prove a causal relationship and to identify the physiological mechanisms responsible. The inclusion of both sleepy and non-sleepy patients in previous studies may explain their heterogeneous results and conclusions. Future interventional studies designed to evaluate the impact of OSA treatment on DM should consider selecting patients with severe OSA who report excessive daytime sleepiness.

Acknowledgements: The authors thank Respiratory Homecare Solutions, Respiratory Wellness Centre, VitalAire and Medigas for participation as recruitment sites for this study. They also thank Marie Flexhaug for her diligent work in ensuring medication accuracy. Braden Manns, William Ghali and Ward Flemons are involved in the longitudinal study assessing healthcare utilisation in this cohort.

Funding: This study was supported by operating grants from the Alberta Heritage Foundation for Medical Research and the Calgary Health Region. BRH and $\mathrm{HO}$ are supported by New Investigator Awards from the Canadian Institutes of Health Research and by Population Health Investigator Awards from the Alberta Heritage Foundation for Medical Research. PER is supported by the Achievers in Medicine Graduate Scholarship.

\section{Competing interests: None.}

Ethics approval: This study was approved by the ethics review board of the University of Calgary.

Provenance and peer review: Not commissioned; externally peer reviewed.

\section{REFERENCES}

1. Marin JM, Carrizo SJ, Vicente E, et al. Long-term cardiovascular outcomes in men with obstructive sleep apnoea-hypopnoea with or without treatment with continuous positive airway pressure: an observational study. Lancet 2005;365:1046-53.

2. Nieto FJ, Young TB, Lind BK, et al. Association of sleep-disordered breathing, sleep apnea, and hypertension in a large community-based study. Sleep Heart Health Study. JAMA 2000;283:1829-36.

3. Peppard PE, Young T, Palta M, et al. Prospective study of the association between sleep-disordered breathing and hypertension. N Engl J Med 2000;342:1378-84.

4. Yaggi HK, Concato J, Kernan WN, et al. Obstructive sleep apnea as a risk factor for stroke and death. N Engl J Med 2005;353:2034-41.

5. Ip MS, Lam B, Ng MM, et al. Obstructive sleep apnea is independently associated with insulin resistance. Am J Respir Crit Care Med 2002;165:670-6.

6. Punjabi NM, Sorkin JD, Katzel LI, et al. Sleep-disordered breathing and insulin resistance in middle-aged and overweight men. Am J Respir Crit Care Med 2002:165:677-82.

7. Vgontzas AN, Papanicolaou DA, Bixler EO, et al. Sleep apnea and daytime sleepiness and fatigue: relation to visceral obesity, insulin resistance, and hypercytokinemia. J Clin Endocrinol Metab 2000;85:1151-8.

8. Al-Delaimy WK, Manson JE, Willett WC, et al. Snoring as a risk factor for type ॥ diabetes mellitus: a prospective study. Am J Epidemiol 2002;155:387-93.

9. Elmasry A, Janson C, Lindberg E, et al. The role of habitual snoring and obesity in the development of diabetes: a 10-year follow-up study in a male population. J Intern Med 2000;248:13-20.

10. Elmasry A, Lindberg E, Berne C, et al. Sleep-disordered breathing and glucose metabolism in hypertensive men: a population-based study. J Intern Med 2001:249:153-61.

11. Grunstein RR, Stenlof K, Hedner J, et al. Impact of obstructive sleep apnea and sleepiness on metabolic and cardiovascular risk factors in the Swedish Obese Subjects (SOS) Study. Int J Obes Relat Metab Disord 1995;19:410-8.
12. Punjabi NM, Shahar E, Redline S, et al. Sleep-disordered breathing, glucose intolerance, and insulin resistance: the Sleep Heart Health Study. Am J Epidemiol 2004; 160:521-30

13. Reichmuth KJ, Austin D, Skatrud JB, et al. Association of sleep apnea and type II diabetes: a population-based study. Am J Respir Crit Care Med 2005;172:1590-5.

14. West SD, Nicoll DJ, Wallace TM, et al. Effect of CPAP on insulin resistance and $\mathrm{HbA1c}$ in men with obstructive sleep apnoea and type 2 diabetes. Thorax 2007:62:969-74.

15. Montserrat JM, Garcia-Rio F, Barbe F. Diagnostic and therapeutic approach to nonsleepy apnea. Am J Respir Crit Care Med 2007;176:6-9.

16. Johns MW. A new method for measuring daytime sleepiness: the Epworth sleepiness scale. Sleep 1991;14:540-5.

17. Vazquez JC, Tsai WH, Flemons WW, et al. Automated analysis of digital oximetry in the diagnosis of obstructive sleep apnoea. Thorax 2000;55:302-7.

18. Mulgrew AT, Fox N, Ayas NT, et al. Diagnosis and initial management of obstructive sleep apnea without polysomnography: a randomized validation study. Ann Intern Med 2007;146:157-66.

19. Whitelaw WA, Brant RF, Flemons WW. Clinical usefulness of home oximetry compared with polysomnography for assessment of sleep apnea. Am J Respir Crit Care Med 2005;171:188-93

20. Hux JE, Ivis F, Flintoft V, et al. Diabetes in Ontario: determination of prevalence and incidence using a validated administrative data algorithm. Diabetes Care 2002:25:512-6.

21. Austin PC, Daly PA, Tu JV. A multicenter study of the coding accuracy of hospital discharge administrative data for patients admitted to cardiac care units in Ontario. Am Heart J 2002;144:290-6.

22. Huzel L, Roos LL, Anthonisen NR, et al. Diagnosing asthma: the fit between survey and administrative database. Can Respir J 2002;9:407-12.

23. Kokotailo RA, Hill MD. Coding of stroke and stroke risk factors using international classification of diseases, revisions 9 and 10. Stroke 2005;36:1776-81.

24. Lee DS, Donovan L, Austin PC, et al. Comparison of coding of heart failure and comorbidities in administrative and clinical data for use in outcomes research. Med Care 2005:43:182-8.

25. Tu K, Campbell NRC, Chen ZL, et al. Accuracy of administrative databases in identifying patients with hypertension. Open Med 2007:1:e3-5

26. Quan H, Sundararajan V, Halfon $\mathrm{P}$, et al. Coding algorithms for defining comorbidities in ICD-9-CM and ICD-10 administrative data. Med Care 2005;43:1130-9.

27. World Health Organization. The international statistical classification of disease and related health problems, 10th revision (ICD-10). Geneva: World Health Organization, 1992.

28. World Health Organization. The international classification of disease, 9th revision Clinical modification. 4th ed. Geneva: World Health Organization, 1996.

29. Pepperell JC, Ramdassingh-Dow S, Crosthwaite N, et al. Ambulatory blood pressure after therapeutic and subtherapeutic nasal continuous positive airway pressure for obstructive sleep apnoea: a randomised parallel trial. Lancet 2002;359:204-10.

30. Young T, Finn L, Peppard PE, et al. Sleep disordered breathing and mortality: eighteen-year follow-up of the Wisconsin sleep cohort. Sleep 2008;31:1071-8.

31. Barbe F, Mayoralas LR, Duran J, et al. Treatment with continuous positive airway pressure is not effective in patients with sleep apnea but no daytime sleepiness: a randomized, controlled trial. Ann Intern Med 2001;134:1015-23.

32. Robinson GV, Smith DM, Langford BA, et al. Continuous positive airway pressure does not reduce blood pressure in nonsleepy hypertensive OSA patients. Eur Respir J 2006:27:1229-35.

33. Jamerson KA, Julius $\mathrm{S}$, Gudbrandsson $\mathrm{T}$, et al. Reflex sympathetic activation induces acute insulin resistance in the human forearm. Hypertension 1993;21:618-23.

34. Pliquett RU, Fasshauer M, Bluher $\mathrm{M}$, et al. Neurohumoral stimulation in type-2 diabetes as an emerging disease concept. Cardiovasc Diabetol 2004;3:4.

35. Morrell MJ, Finn L, Kim H, et al. Sleep fragmentation, awake blood pressure, and sleep-disordered breathing in a population-based study. Am J Respir Crit Care Med 2000;162:2091-6.

36. Spiegel K, Tasali E, Penev P, et al. Brief communication: Sleep curtailment in healthy young men is associated with decreased leptin levels, elevated ghrelin levels, and increased hunger and appetite. Ann Intern Med 2004;141:846-50.

37. Spiegel K, Knutson K, Leproult R, et al. Sleep loss: a novel risk factor for insulin resistance and Type 2 diabetes. J Appl Physiol 2005;99:2008-19.

38. Vgontzas AN, Papanicolaou DA, Bixler EO, et al. Elevation of plasma cytokines in disorders of excessive daytime sleepiness: role of sleep disturbance and obesity. J Clin Endocrinol Metab 1997;82:1313-6.

39. Dimsdale JE, Coy T, Ziegler MG, et al. The effect of sleep apnea on plasma and urinary catecholamines. Sleep 1995;18:377-81.

40. Spiegel K, Leproult R, Van Cauter E. Impact of sleep debt on metabolic and endocrine function. Lancet 1999;354:1435-9.

41. Strohl KP, Boehm KD, Denko CW, et al. Biochemical morbidity in sleep apnea. Ear Nose Throat J 1993; 72:34-41. 